\title{
Pessimism, diet, and the ability to improve dietary habits: a three-year follow-up study among middle-aged and older Finnish men and women
}

Mikko Pänkäläinen ${ }^{1 *}$ (D) Mikael Fogelholm² ${ }^{2}$ Raisa Valve ${ }^{2}$, Olli Kampman $^{3,4}$, Markku Kauppi $^{4,5}$, Erja Lappalainen ${ }^{1}$ and Jukka Hintikka ${ }^{1,4}$

\begin{abstract}
Background: Dietary habits have a great influence on physiological health. Even though this fact is generally recognized, people do not eat as healthily as they know they should. The factors that support a healthy diet, on the other hand, are not well known. It is supposed that there is a link between personal traits and dietary habits. Personal traits may also partially explain why some people manage to make healthy dietary changes while some fail to do so or are not able to try to make changes even when they desire to do so. There is some information suggesting that dispositional optimism plays a role in succeeding in improving dietary habits. The aim of this study was to determine the role of optimism and pessimism in the process of dietary changes.
\end{abstract}

Methods: Dispositional optimism and pessimism were determined using the revised Life Orientation Test in 2815 individuals (aged 52-76 years) participating in the GOAL study in the region of Lahti, Finland. The dietary habits of the study subjects were analysed. After 3 years, the subjects' dietary habits and their possible improvements were registered. The associations between dispositional optimism and pessimism, dietary habits at baseline, and possible changes in dietary habits during the follow-up were studied with logistic regression. We also studied if the dietary habits or certain lifestyle factors (e.g. physical exercising and smoking) at baseline predicted success in improving the diet.

Results: Pessimism seemed to correlate clearly negatively with the healthiness of the dietary habits at baseline - i.e. the higher the level of pessimism, the unhealthier the diet. Optimism also showed a correlation with dietary habits at baseline, although to a lesser extent. Those who managed to improve their dietary habits during follow-up or regarded their dietary habits as healthy enough even without a change were less pessimistic at baseline than those who failed in their attempts to improve their diet or did not even try, even when they recognized the need for a change.

Conclusions: Pessimistic people are more likely to eat an unhealthy diet than others. Pessimism reduces independently the possibilities to improve dietary patterns.

Keywords: Pessimism, Optimism, Life orientation test - revised, Dietary habits

\footnotetext{
* Correspondence: mikko.pankalainen@phsotey.fi

'Department of Psychiatry, Päijät-Häme Central Hospital, Keskussairaalankatu

7, Fl-15850 Lahti, Finland

Full list of author information is available at the end of the article
}

(c) The Author(s). 2018 Open Access This article is distributed under the terms of the Creative Commons Attribution 4.0 International License (http://creativecommons.org/licenses/by/4.0/), which permits unrestricted use, distribution, and reproduction in any medium, provided you give appropriate credit to the original author(s) and the source, provide a link to the Creative Commons license, and indicate if changes were made. The Creative Commons Public Domain Dedication waiver (http://creativecommons.org/publicdomain/zero/1.0/) applies to the data made available in this article, unless otherwise stated. 


\section{Background}

Despite the well-known connection between dietary habits and health, many people do not eat what is recommended as a healthy diet [1]. Dietary habits are related e.g. to the risk of coronary heart disease (CHD) [2] and improving dietary habits has showed significant cardioprotective effects in a secondary prevention program among women with CHD [3].

While the intention to prevent diseases is usually thought to be an important reason for a healthier diet, psychosocial and lifestyle related factors seem to be one of the major causes for not eating healthily. The most common factors mentioned in preventing a healthy diet are a lack of time, a reluctance to give up favourite foods, and a lack of motivation and willpower [4-6]. A healthy diet is also thought to be more expensive than unhealthy one, even if this belief seems to be false $[7,8]$.

The terms optimism and its antonym pessimism derive from Latin words 'optimus' and 'pessimus', respectively (the first meaning 'the best' and the latter meaning 'the worst' [9]) and they are used in describing people's outlook and expectations concerning their future. Persons who have a feeling or belief that good things will happen in the future are called optimists and they are said to see "the glass as half-full rather than half-empty". Pessimists in turn generally feel that bad things are more likely to happen than good things [10]. Optimism is regarded in psychology as a cognitive, affective and motivational construct [11]. On other words, optimists not only think, but also feel positively about the future. Like other personal trait, also optimism and pessimism develop during the childhood and early adulthood influenced by both heritage and environment [12, 13], and unlike e.g. mood, the construct of optimism (including both optimistic and pessimistic properties) is thought to be quite stable after it has evolved, regardless of negative or positive incidents $[14,15]$.

People are often categorized as optimists or pessimists. This can lead to the conclusion that optimism and pessimism are the two extremities of the same unidimensional continuum (dispositional optimism). Nevertheless, the concept of optimism itself has long been controversial: there is debate over whether the optimism construct should be seen as one bipolar dimension or if optimism and pessimism should be seen as two separate dimensions that exist simultaneously and may be unattached to each other.

Optimism is sometimes confused with other concepts, e.g. features like the sense of control [16], self-efficacy [17] and hope [18]. There are still differences with these terms. Unlike the concept of optimism, these properties include also how the desired outcomes are expected to happen. For example, a person with high self-efficacy believes that his/her personal efforts or skills are what will determine the positive outcome while an optimist does not rely on his/her own abilities.

Numerous psychosocial factors have been noted to influence dietary behaviour. A connection seems to exist between psychosocial features and current diet, and also between psychosocial features and the ability to improve the diet. Psychosocial features of interest include e.g. socio-economic status, willpower, self-efficacy, and satisfaction with life. There are many studies on the associations between these psychosocial factors and healthy eating [4, 19-24], but the number of studies concerning the optimism construct and dietary habits is quite small. The findings of these few studies suggest that there might be a positive connection between optimism and the willingness and capability to eat in a healthier way [25-29]. In all of these studies on the connection between the optimism construct and dietary habits, optimism has been associated with healthier diet and/or pessimism vice versa. In a study on young Finnish adults, unipolarly measured optimism had an influence on dietary habits, and pessimism was linked to an unhealthy diet [25]. In a study on elderly men, a low level of optimism was associated with an unhealthy lifestyle, including unhealthy dietary habits [29]. In the large Women's Health Initiative study, high optimism was strongly related to healthier eating habits and greater levels of success in improving dietary habits [26, 27]. In a study on Polish menopausal women, optimism was positively correlated with a healthier diet [28]. However, we did not find any previous studies with general population samples focusing on the dietary habits and the optimism construct that would handle optimism and pessimism as independent factors. We conducted this 3-year follow-up study on middle-aged and older Finnish men and women to determine whether optimism and pessimism are factors that associate with dietary habits and predict success in improving those habits.

\section{Methods}

The GOAL study (Good Ageing in Lahti Region) started in 2002. Its aim was to determine and improve the health and well-being of the ageing population of the region of Lahti, a city in southern Finland. The entire project consisted of a cohort study and several communitybased interventions and it lasted for 10 years. In the present study, data from baseline (year 2002) and 3-year follow-up (year 2005) of the cohort study were used.

The cohort study group consisted of a stratified (age, sex, municipality) random sample of men and women born in 1926-30, 1936-40, and 1946-50. The study participants were drawn from the population registry of all 14 municipalities in the Lahti region. A total of 4272 subjects were invited, and 2815 (66\%) participated. 
At the beginning of the GOAL study, cross-sectional data on the dietary habits, current health, and lifestyles of the study subjects were gathered by using questionnaires. The study subjects were asked about their recent dietary habits with a food frequency questionnaire (FFQ) where different foods were divided into 24 categories. The respondents were asked how often they had consumed the foods in each category during the last 7 days. The answers were scaled from 1 (not at all) to 4 (on 6 or 7 days). Study subjects were measured for height and weight and their body mass indexes (BMI) were calculated. According to their smoking habits, the study subjects were divided into two groups, 'daily smokers' (i.e. those who smoked every day, regardless of the amount) and 'non-daily smokers'. Study subjects who used five or more units of alcohol (one unit $=12 \mathrm{~g} \mathrm{EtOH}$ ) in one sitting formed the 'heavy drinkers' group, while the rest were 'non-heavy drinkers'. The study subjects were asked if they had been diagnosed with CHD by a doctor. Finally, the subgroup 'regular physical exercise' was formed to include those who exercised for $30 \mathrm{~min}$ at least twice a week. In addition to the questionnaires, several blood tests were taken. The samples were measured for the levels of blood glucose and cholesterol, among other things.

Levels of dispositional optimism and pessimism were measured by using the revised version of the Life Orientation Test (LOT-R). The test was initially developed in the mid-1980s to assess the beneficial effects of optimism on psychological and physiological health (Life Orientation Test (LOT)) [30]. The scale was re-evaluated and revised (LOT-R) later to focus its item content more closely on the subject's expectations of the future [31].

LOT-R includes six statements, three worded positively for optimism (e.g. 'In uncertain times, I usually expect the best') and three worded negatively to indicate pessimism (e.g. 'If something can go wrong for me, it will'). The respondents are asked to indicate how much they agree with the statements in general, as expressed on a scale from 0 ('I disagree a lot') to 4 ('I agree a lot'). A higher score refers to greater optimism or greater pessimism depending on the statement. Originally, both LOT and LOT-R were thought to be unidimensional scales, but later studies have suggested that they may have two separate independent dimensions, namely optimism and pessimism [32-36]. In the one-dimensional bipolar model with optimism and pessimism as opposites, the optimism scores and pessimism scores are calculated together and they might cancel out and hide each other's results. Our previous study showed clearly that in this study sample, LOT-R has two separate subscales: optimism and pessimism [37]. Thus, in the final analyses, we used the independent scores separately for optimism and pessimism.
After 3 years, in 2005, the study subjects were examined again. A total of 2625 subjects (93\% of the original sample) had adequate responses in both 2002 and 2005, and could therefore be included in the final analyses. In 2005 , the study subjects were asked if they had tried to improve or were about to improve their dietary habits, and if they had tried to improve their diet, how had they managed to achieve their goals. The possible improving styles in the diet were divided into five subgroups: reducing the consumption of fat, changing to low-fat products, reducing the consumption of sugar, increasing the consumption of vegetables, and increasing the consumption of berries and fruits.

We divided the study subjects in these five subgroups of different improving styles into four categories according to the possible changes in their diets: 1) those who had not tried to change their eating habits to a healthier diet, even when they thought it would have been beneficial, 2) those who thought their dietary habits were healthy enough even without an improvement, 3) those who had succeeded in improving of their diet, and 4) those who had tried to improve their diet but had failed to do so.

In the statistical analyses, we created dietary pattern models for grouping of the sample by using principal component analysis (PCA) with Varimax rotation and Kaiser normalization. Factor loadings with $>0.35$ were considered as significant. Student's t-test was used to study the associations between optimism, pessimism, and the different dietary patterns. When studying the differences in levels of optimism and pessimism, according to the success in the improvement of dietary habits in four categories, we used the Kruskal-Wallis test due to skewed distributions.

Finally, we calculated logistic regression models to discover the fully adjusted odds ratios for different variables for the risk of not succeeding in improving dietary habits.

\section{Results}

Using the data from the food frequency questionnaire in 2002, we divided the study subjects into different dietary pattern groups by using principal component analysis. The analysis resulted in four nearly independent dietary patterns, which we named as 'healthy', 'sweet unhealthy', 'fatty unhealthy' and 'traditional' diets (Table 1). In further analyses, principal component analysis scores were used as independent variables to describe the amount of each different dietary pattern in the study subjects. We used the medians of the LOT-R optimism and pessimism subscale scores to classify the study subjects into low and high optimism and pessimism groups. Principal component analysis scores were compared between these groups (Table 2).

At baseline, higher optimism and lower pessimism were associated with a 'healthy' dietary pattern. Optimism and pessimism did not seem to play any role in 
Table 1 Rotated factor matrix for dietary patterns created by using principal component analysis. Factor loadings with absolute values of $>0.35$ have been presented in bold. Negative loadings indicate the lack of foodstuff in question belonging to certain dietary patterns

\begin{tabular}{|c|c|c|c|c|}
\hline \multirow[t]{2}{*}{ Foodstuff } & \multicolumn{4}{|c|}{ Dietary pattern } \\
\hline & Healthy & Sweet unhealthy & Fatty unhealthy & Traditional \\
\hline Porridge, cereals & 0.382 & -0.001 & -0.152 & 0.249 \\
\hline Fish & 0.397 & -0.109 & 0.060 & -0.097 \\
\hline Lunch meats, cold cuts & 0.359 & 0.214 & 0.055 & 0.142 \\
\hline Fresh vegetables/root vegetables & 0.664 & -0.018 & -0.131 & 0.005 \\
\hline Cooked vegetables & 0.646 & -0.049 & -0.032 & -0.098 \\
\hline Berries and fruits & 0.589 & 0.076 & -0.171 & 0.181 \\
\hline Fruit or berry juice & 0.378 & 0.081 & 0.189 & 0.037 \\
\hline Sweet pastries & 0.109 & 0.597 & -0.031 & 0.256 \\
\hline Ice cream & 0.088 & 0.495 & 0.085 & -0.131 \\
\hline Candies & -0.043 & 0.701 & 0.033 & 0.078 \\
\hline Chocolate & 0.035 & 0.677 & 0.098 & -0.032 \\
\hline Salty snacks & -0.024 & 0.352 & 0.195 & -0.221 \\
\hline Fried potatoes, French fries & -0.005 & 0.026 & 0.489 & -0.059 \\
\hline Low-fat cheese & 0.411 & 0.142 & -0.368 & -0.066 \\
\hline Other cheese & -0.004 & 0.025 & 0.609 & 0.108 \\
\hline Sausages & -0.147 & 0.240 & 0.493 & 0.065 \\
\hline Sliced sausages & -0.111 & 0.139 & 0.558 & 0.053 \\
\hline Eggs & 0.151 & 0.013 & 0.475 & -0.057 \\
\hline Soft drinks & -0.103 & 0.305 & 0.352 & -0.125 \\
\hline Meat dishes & 0.028 & 0.132 & 0.366 & 0.552 \\
\hline Chicken, turkey & 0.443 & 0.003 & -0.048 & -0.415 \\
\hline Boiled or mashed potatoes & 0.230 & 0.002 & 0.101 & 0.658 \\
\hline Rice, pasta & 0.294 & 0.088 & 0.115 & -0.409 \\
\hline Pizza, hamburgers & -0.021 & 0.263 & 0.169 & -0.302 \\
\hline
\end{tabular}

the 'sweet unhealthy' and 'traditional' dietary patterns, but high pessimism and the 'fatty unhealthy' dietary pattern associated significantly (Table 2).

The association between changes in dietary habits during the 3-year follow-up and pessimism was quite clear (Table 3). There was a strong trend that those who managed to change to a healthier diet were less pessimistic compared to others. The differences were statistically significant in four dietary categories: reducing fat, changing to low-fat products, increasing vegetables, and increasing berries and fruits. The higher the level of pessimism, the less likely was the improvement of diet. Nevertheless, those who had tried but failed reducing sugar were not more pessimistic than others. Optimism was associated with only one dietary change; those who had tried but failed to increase consumption of berries and fruits were less optimistic than others.

Table 2 Comparisons of principal component analysis scores of dietary patterns between groups with low or high pessimism, and low or high optimism

\begin{tabular}{|c|c|c|c|c|c|c|c|c|}
\hline & \multicolumn{8}{|c|}{ Principal component analysis scores (mean) } \\
\hline & $\begin{array}{l}\text { Healthy dietary } \\
\text { pattern }\end{array}$ & $p^{1}$ & $\begin{array}{l}\text { Sweet unhealthy } \\
\text { dietary pattern }\end{array}$ & $p^{1}$ & $\begin{array}{l}\text { Fatty unhealthy } \\
\text { dietary pattern }\end{array}$ & $p^{1}$ & $\begin{array}{l}\text { Traditional } \\
\text { dietary pattern }\end{array}$ & $p^{1}$ \\
\hline Low pessimism $(N=1274)^{2}$ & 0.071 & & 0.029 & & -0.048 & & -0.006 & \\
\hline High pessimism $(N=1351)^{3}$ & -0.066 & $<0.001$ & -0.027 & 0.153 & 0.046 & 0.016 & 0.006 & 0.762 \\
\hline Low optimism $(N=1210)^{2}$ & -0.085 & & 0.000 & & -0.019 & & 0.026 & \\
\hline High optimism $(N=1415)^{3}$ & 0.073 & $<0.001$ & -0.000 & 0.995 & 0.016 & 0.365 & -0.022 & 0.213 \\
\hline
\end{tabular}

${ }^{1}$ Student's t-test; ${ }^{2}$ Below the median; ${ }^{3}$ Median or higher

$\mathrm{p}^{1}$-scores indicating statistical significance are bolded 
Table 3 The association between optimism and pessimism, and the change in dietary habits

\begin{tabular}{|c|c|c|c|c|c|}
\hline & Has not changed & No need to change & Has changed & $\begin{array}{l}\text { Tried to change, } \\
\text { but failed }\end{array}$ & $p^{1}$ \\
\hline Reducing fat & $N=82$ & $N=1059$ & $N=1280$ & $N=204$ & \\
\hline Optimism (Mean (SD)) & $8.60(2.02)$ & $8.26(2.24)$ & $8.39(2.08)$ & $8.18(2.14)$ & 0.385 \\
\hline Pessimism (SD) & $4.59(2.60)$ & $4.19(2.79)$ & $3.62(2.58)$ & $4.44(2.81)$ & $<0.001$ \\
\hline Changing to low-fat products & $N=155$ & $N=1098$ & $N=1266$ & $N=106$ & \\
\hline Optimism (Mean (SD)) & $8.37(2.20)$ & $8.28(2.21)$ & $8.39(2.09)$ & $8.18(2.15)$ & 0.674 \\
\hline Pessimism (Mean (SD)) & $4.46(2.74)$ & $4.15(2.77)$ & $3.65(2.60)$ & $4.47(2.76)$ & $<0.001$ \\
\hline Increasing vegetables & $N=198$ & $N=1141$ & $N=1090$ & $N=196$ & \\
\hline Optimism (Mean (SD)) & $8.46(2.16)$ & $8.25(2.28)$ & $8.43(2.01)$ & $8.10(2.06)$ & 0.058 \\
\hline Pessimism (Mean (SD)) & $4.10(2.69)$ & $4.09(2.77)$ & $3.69(2.59)$ & $4.43(2.79)$ & $<0.001$ \\
\hline Reducing sugar & $N=110$ & $N=1287$ & $N=986$ & $N=242$ & \\
\hline Optimism (Mean (SD)) & $8.23(2.13)$ & $8.29(2.23)$ & $8.42(2.04)$ & $8.17(2.18)$ & 0.520 \\
\hline Pessimism (Mean (SD)) & $4.16(2.54)$ & $4.04(2.75)$ & $3.78(2.69)$ & $3.95(2.54)$ & 0.145 \\
\hline Increasing berries and fruits & $N=128$ & $N=1520$ & $N=859$ & $N=118$ & \\
\hline Optimism (Mean (SD)) & $8.38(2.05)$ & $8.39(2.20)$ & $8.32(2.05)$ & $7.81(2.22)$ & 0.041 \\
\hline Pessimism (Mean (SD)) & $4.43(2.77)$ & $4.02(2.78)$ & $3.68(2.51)$ & $4.35(2.72)$ & 0.002 \\
\hline
\end{tabular}

${ }^{1}$ Kruskal-Wallis test

$\mathrm{p}^{1}$-scores indicating statistical significance are bolded

Finally, we calculated multivariate logistic regression models including several predicting variables for the risk of failure in improving dietary habits (Table 4). Because of the relatively small subgroups, we combined those who had failed in their dietary changes with those who had not even tried to improve their diet even when they recognized the need to do so into one group. We also combined those who saw no need to improve their diets with those who had managed to make healthy changes into another group.

The models included different dietary patterns, age, sex smoking and alcohol consumption habits, physical exercise, the levels of blood glucose and cholesterol, body mass index, the possible existence of $\mathrm{CHD}$, and pessimism as explaining variables. A fatty unhealthy dietary pattern associated with the risk of failure in changing to low-fat products and in increasing vegetables. Sweet unhealthy dietary pattern associated with the risk of failure in increasing vegetables, in reducing sugar and in increasing berries and fruits. Finally, the effect of pessimism seemed clear in three out of five subgroups. Pessimism increased the probability of failure in reducing fat, changing to low-fat products, and increasing the consumption of berries and fruits.

To emphasize the association between pessimism and failures in changing dietary habits, we compared the highest and the lowest quarters of pessimism in logistic regression models which were fully adjusted for age, sex,

Table 4 Odds ratios of different dietary pattern groups, coronary heart disease and pessimism (rows) on the risk of failure in change to more healthy dietary habits (columns) analysed by logistic regression models ${ }^{a}$

\begin{tabular}{|c|c|c|c|c|c|c|c|c|c|c|}
\hline & \multicolumn{10}{|c|}{ Dietary change } \\
\hline & \multicolumn{2}{|c|}{$\begin{array}{l}\text { No change and fail } \\
\text { in reducing fat }\end{array}$} & \multicolumn{2}{|c|}{$\begin{array}{l}\text { No change and fail in } \\
\text { changing to low-fat } \\
\text { products }\end{array}$} & \multicolumn{2}{|c|}{$\begin{array}{l}\text { No change and fail in } \\
\text { increasing vegetables }\end{array}$} & \multicolumn{2}{|c|}{$\begin{array}{l}\text { No change and fail } \\
\text { in reducing sugar }\end{array}$} & \multicolumn{2}{|c|}{$\begin{array}{l}\text { No change and fail in } \\
\text { increasing berries and } \\
\text { fruits }\end{array}$} \\
\hline & $\overline{O R}$ & $95 \% \mathrm{Cl}$ & $\overline{O R}$ & $95 \% \mathrm{Cl}$ & $\overline{O R}$ & $95 \% \mathrm{Cl}$ & $\overline{O R}$ & $95 \% \mathrm{Cl}$ & $\overline{O R}$ & $95 \% \mathrm{Cl}$ \\
\hline Healthy dietary pattern & 0.87 & $0.76-1.00$ & 0.88 & $0.76-1.01$ & 0.79 & $0.70-0.89$ & 0.92 & $0.82-1.04$ & 0.75 & $0.65-0.86$ \\
\hline Sweet unhealthy dietary pattern & 1.13 & $0.99-1.29$ & 1.07 & $0.94-1.23$ & 1.26 & $1.13-1.40$ & 1.30 & $1.16-1.45$ & 1.23 & $1.08-1.40$ \\
\hline Fatty unhealthy dietary pattern & 1.10 & $0.96-1.26$ & 1.14 & $1.00-1.31$ & 1.17 & $1.05-1.32$ & 1.03 & $0.92-1.16$ & 1.13 & $0.98-1.30$ \\
\hline Traditional dietary pattern & 1.12 & $0.98-1.27$ & 1.02 & $0.90-1.17$ & 0.97 & $0.87-1.08$ & 1.01 & $0.90-1.14$ & 0.89 & $0.78-1.02$ \\
\hline Coronary heart disease & 1.07 & $0.66-1.73$ & 0.91 & $0.54-1.54$ & 1.20 & $0.81-1.80$ & 1.52 & $1.00-2.31$ & 1.41 & $0.87-2.28$ \\
\hline Pessimism & 1.07 & $1.02-1.12$ & 1.07 & $1.02-1.13$ & 1.03 & $0.99-1.07$ & 1.02 & $0.98-1.07$ & 1.05 & $1.00-1.11$ \\
\hline
\end{tabular}


smoking and alcohol consumption habits, physical exercise, the levels of glucose, cholesterol, body mass index and the possible existence of CHD. Those who belonged to the highest quarter of pessimism had a 1.4-fold risk of not succeeding in reducing their consumption of fat (adjusted OR 1.44, 95\% CI 1.00-2.08, $p=0.05$ ), a 1.5-fold risk of not succeeding in changing to low-fat products (adjusted OR 1.51, 95\% CI 1.03-2.21, $p=0.03$ ), and a 1.5 -fold risk of failing to increase the consumption of berries and fruits in their diet (adjusted OR 1.46, 95\% CI $1.01-2.12, p=0.02$ ) compared to the study subjects in the lowest quarter of pessimism.

\section{Discussion}

Our main findings were that the dietary habits of study subjects with a higher level of pessimism were unhealthier compared to the dietary habits of others, and that the high level of pessimism was associated with greater difficulties in improving dietary habits. High levels of pessimism have been linked independently with an elevated risk of CHD [37-39]. While pessimism seems to be an independent risk factor for $\mathrm{CHD}$, our results suggest that it may also be related to increased risk of CHD via an unhealthier diet.

There seemed to be no association between sweet unhealthy dietary pattern as well as fail in reducing sugar and optimism/pessimism. It has been speculated that the physiological and psychological mechanisms concerning sugar consumption might be different compared to the mechanism of other dietary habits. For example, when trying to eat healthily, the lack of sweet foods is often seen as the most difficult task [40] and when treating binge eating with baclofen, the medication seems to suppress binge eating of pure fat but not a sugar-rich diet [41].

It can be discussed whether the test subjects had proper information about good dietary habits, but it has been stated that the factor preventing people from eating healthy is not a lack of knowledge but rather the fact that people do not eat as healthily they know they should $[1,42,43]$. While there are many different recommendations about healthy diets which can make it challenging to know how to eat healthily it also seems that the correlation between nutrition knowledge and healthy dietary intake is quite weak [44].

Our study also strengthens the idea of optimism and pessimism as two different and independent variables. The statistical power of the optimism subscale was very small, while pessimism had stronger associations with several outcomes.

Improving the diet has a role in both prevention and treatment of several chronic diseases. The result of our study - pessimism being associated with difficulties in improving one's diet - is parallel with earlier studies on psychosocial factors and adherence to various treatments. For example, adherence to treatment of asthma patients, hypertensive patients, cardiac patients, and rehabilitation patients after surgery seemed to relate to psychosocial factors, including dispositional optimism [45-48]. A higher level of optimism has also been associated, for example, with greater success in achieving good results in health changes among cardiac patients $[49,50]$ and in dental health [51]. Optimism and good compliance to treatment might also be connected in HIV patients [52].

An earlier study suggested that optimistic people exert greater efforts at goal attainment than pessimists do, for example, in alcoholism treatment [53]. In cross-sectional analyses, optimists have been shown to choose healthier foods when no preceding instructions are given $[54,55]$. According to these studies, it seems that dispositional optimism and pessimism relate to the motivation in the treatment compliance, overall health behaviour, and the ability to make changes in lifestyle in order to improve physical well-being. The results of our study strengthen this claim.

As mentioned, there are some previous studies on associations between optimism/pessimism and dietary patterns [25-29]. However, there are some shortcomings in these studies. In these studies optimism and pessimism were dealt as a bipolar, single variable, and except for one study, the study participants were all of the same gender. It has been recognized in many other studies that optimism and pessimism are probably two independent variables that are present at same the time - i.e. one has both pessimistic and optimistic traits simultaneously [35]. The method of using optimism and pessimism as two different dimensions rather than one bipolar single variable may reveal much more information when the opposite ends of the bipolar variable do not cancel each other [32-36]. Separating optimism from pessimism turned out to be beneficial also in our study; optimism and pessimism seemed to be two different and independent factors as optimism seemed to have a connection with only one type of change in diet, while pessimism was associated much more strongly with many dietary behaviour changes. This endorses the need to separate optimism and pessimism to achieve more accurate results. Analysing optimism and pessimism as a unidimensional variable in this study would probably have covered some of the current results.

It has also been suggested that dispositional optimism might be a unidimensional continuum, but questions oriented pessimistically are better in determining this variable [54], thus diminishing the statistical power of optimistically oriented questions.

Even if it seems that people with high levels of pessimism have an unhealthier diet than others do and they are less likely to be able to change their dietary habits, it has been found that after proper education and monitoring, the association between pessimism and the ability to improve diet disappears. This conclusion was drawn 
following a trial derived from the GOAL study [56]. In the study, the subjects with higher pessimism levels had unhealthier lifestyles, including unhealthier dietary habits. However, after the pessimists had received education concerning healthier lifestyles and were subjected to close monitoring, they managed to improve their lifestyles equally to other subjects. Keeping this in mind, it would seem only natural that determining pessimism could help in finding those who probably have unhealthier diets and are in greater risk in failing to improve them. Those subjects could then be targeted with proper education about healthy diets, and the monitoring of dietary changes could lower the risk of various diseases. Naturally, the independent risk of pessimism in developing those illnesses - for example, CHD - is still unlikely to diminish. Determining the level of dispositional pessimism is quick to assess and practically cost free, so it can be expected to be very cost-effective.

There are some strengths and weaknesses in our study and methods. The population was drawn as a random sample and it is representative of Lahti Region with 200,000 inhabitants. However, it seems that poorly functioning and institutionalized persons had a lower participation rate than community-dwelling subjects [57]. The design is longitudinal and observational, but it can obviously not detect any causality between the assessed variables. We have measured a great number of variables, hence the possibility to adjust for a number of confounders was good. However, and typical of cohort studies, the methods were mostly simple and we were unable to describe the diet by, e.g., an extensive food-frequency questionnaire. In the analyses, we classified reduction of fat as an indication of a healthy change. This may of course be debated, since more recent studies indicate that fat quality (shift from saturated towards unsaturated fats) is more important than the intake of total fat per se [58]. In early 2000's, reductions in dietary fat and in fatty foods were generally - at least among many lay individuals regarded as healthy. Hence, we chose to use fat reduction as an indication of a choice to improve dietary quality.

Much of the data used in this study is based on self-rated questionnaires, so there might be some inconsistency between the answers and the reality in the questions concerning, for example, smoking habits and use of alcohol.

\section{Conclusions}

Dietary habits play an important role in the development of many diseases, and improving the diet reduces the risk for developing many severe illnesses. Pessimism and to some extent optimism seem to play a role in current dietary habits and in the ability to change these habits. By determining optimism and particularly pessimism, it is possible to detect individuals in greater need of guidance and support in ameliorating their dietary habits.
Separating optimism and pessimism seems to make a clearer connection between the optimism construct and dietary habits as well as between the optimism construct and the ability to make healthy dietary changes.

\section{Abbreviations \\ BMI: Body mass index; CHD: Coronary heart disease; FFQ: Food frequency questionnaire; GOAL: Good Ageing in Lahti Region study; LOT: Life orientation test; LOT-R: Revised version of the life orientation test; PCA: Principal component analysis}

\section{Acknowledgements}

We thank all the participants in the GOAL Project.

\section{Funding}

This study was supported with an EVO (special state funding) grant from Päijät-Häme Central Hospital.

\section{Availability of data and materials}

The dataset supporting the conclusions of this article is a part of the GOAL (Good Ageing in Lahti Region) Project and it was collected and is preserved by the Palmenia Centre for Continuing Education in Lahti, Finland.

\section{Authors' contributions}

Authors MP and JH designed the study. RV, MF, OK, MK and EL participated in the conception of the study. $\mathrm{JH}$ managed and conducted the statistical analyses and interpreted the data. MP wrote the first draft and MP, JH, RV, MF, OK, MK and EL revised it to make the final manuscript. All authors have approved the final manuscript.

\section{Ethics approval and consent to participate}

The cohort study was approved in 2002 by the Ethics Committee of PäijätHäme Central Hospital, which is located in the city of Lahti, and this extension study was approved in 2013 by the Ethics Committee of Pirkanmaa Hospital District (R12013). Written informed consent was requested and obtained from all cohort participants in 2002.

\section{Consent for publication}

Not applicable.

\section{Competing interests}

The authors declare that they have no competing interests.

\section{Publisher's Note}

Springer Nature remains neutral with regard to jurisdictional claims in published maps and institutional affiliations.

\section{Author details}

${ }^{1}$ Department of Psychiatry, Päijät-Häme Central Hospital, Keskussairaalankatu 7, FI-15850 Lahti, Finland. 'Department of Food and Environmental Sciences, University of Helsinki, Helsinki, Finland. ${ }^{3}$ Department of Psychiatry, Seinäjoki Hospital District, Seinäjoki, Finland. ${ }^{4}$ School of Medicine, University of

Tampere, Tampere, Finland. ${ }^{5}$ Department of Internal Medicine, Päijät-Häme Central Hospital, Lahti, Finland.

Received: 30 December 2017 Accepted: 1 October 2018 Published online: 15 October 2018

\section{References}

1. Guenther PM, Casavale KO, Kirkpatrick SI, Reedy J, Hiza HAB, Kuczynski KJ Kahle LL, Krebs-Smith SM. Diet quality of Americans in 2001-02 and 2007-08 as measured by the healthy eating Index-2010. Nutrition Insight. 2013;51.

2. Schwingshackl L, Hoffmann G. Diet quality as assessed by the healthy eating index, the alternate healthy eating index, the dietary approaches to stop hypertension score, and health outcomes: a systematic review and meta-analysis of cohort studies. J Acad Nutr Diet. 2015;5:780-800.

3. de Lorgeril M, Patricia S, Martin J-L, Monjaud I, Delaye J, Mamelle N. Mediterranean diet, traditional risk factors, and the rate of cardiovascular complications after myocardial infarction: final report of the Lyon diet heart study. Circulation. 1999;6:779-85. 
4. Lappalainen R, Saba A, Holm L, Mykkänen H, Gibney MJ. Difficulties in trying to eat healthier: descriptive analysis of perceived barriers for healthy eating. Eur J Clin Nutr. 1997;51:36-40.

5. López-Azpiazu I, Martínez-González MA, Kearney J, Gibney M, Martínez JA Perceived barriers of, and benefits to, healthy eating reported by a Spanish national sample. Public Health Nutr. 1998;2:209-15.

6. Andajani-Sutjahjo S, Ball K, Warren N, Inglis V, Crawford D. Perceived personal, social and environmental barriers to weight maintenance among young women: a community survey. Int J Behav Nutr Phys Act. 2004;1:7.

7. Mitchell DC, Shannon BM, Mckenzie J, Smiciklas-Wright H, Miller BM, Tershakovec AM. Lower fat diets for children did not increase food costs. J Nutr Educ. 2000;32:100-3.

8. Goulet J, Lamarche B, Lemieux S. A nutritional intervention promoting a Mediterranean food pattern does not affect total daily dietary cost in north American women in free-living conditions. J Nutr. 2008;138:54-9.

9. Lewis CT, Short C. A Latin dictionary. Oxford: Oxford Press; 1879.

10. Cambridge Free English Dictionary and Thesaurus. Cambridge University Press. http://dictionary.cambridge.org/. Accessed 8 June 2018.

11. Peterson C. The future of optimism. Am Psychol. 2000;55:44-55.

12. Schulman P, Keith D. Seligman MEP. Is optimism heritable (a study of twins). Behav Res Ther. 1993:6:569-74.

13. Mosing MA, Medland SE, McRae A, Landers JG, Wright MJ, Martin NG. Genetic influences on life span and its relationship to personality: a 16-year follow-up study of a sample of aging twins. Psychosom Med. 2012;74:16-22.

14. Billingsley KD, Waehler CA, Hardin SI. Stability of optimism and choice of coping strategy. Percept Mot Skills. 1993;76:91-7.

15. Schou I, Ekeberg O, Sandvik L, Ruland CM. Stability in optimism-pessimism in relation to bad news: a study of women with breast cancer. J Pers Assess. 2005;2:148-54.

16. Thompson SC. The role of personal control in adaptive functioning. In: Snyder CR, Lopez SJ, editors. Handbook of positive psychology. New York: Oxford University Press; 2002. p. 202-13.

17. Bandura A. Self-efficacy: the exercise of control. New York: Freeman; 1997.

18. Snyder CR. The psychology of hope: you can get there from here. New York: Free Press; 1994.

19. de Ridder D, Kroese F, Evers C, Adriaanse M, Gillebaart M. Healthy diet health impact, prevalence, correlates. and interventions Psychology \& Health. 2017;32:907-41

20. Brownell KD, Cohen LR. Adherence to dietary regimen 2: components of effective intervention. Behav Med. 1995;20:155

21. Strachan SM, Brawley LR. Healthy-eater identity and self-efficacy predict healthy eating behavior. J Health Psychol. 2009;14:684-95.

22. van de Rest O, de Goede J, Sytsma F, Oude Griep LM, Geleijnse JM, Kromhout D, Giltay EJ. Association of n-3 long chain PUFA and fish intake with depressive symptoms an low dispositional optimism in older subjects with a history of myocardial infarction. Br J Nutr. 2010;103:1381-7.

23. Kumanyika SK, Bowen D, Rolls BJ, Von Horn L, Perri MG, Czajkowski SM, Schron E. Maintenance of dietary behavior change. Health Psychol. 2000; 19:42-56.

24. Steptoe A, Doherty S, Kerry S, Rink E, Hilton S. Sociodemographic and psychological predictors of changes in dietary fat consumption in adults with high blood cholesterol following counselling in primary care. Health Psychol. 2000;19:411-9.

25. Kelloniemi H, Ek E, Laitinen J. Optimism, dietary habits, body mass index and smoking among young Finnish adults. Appetite. 2005:45:169-76.

26. Tinker LF, Rosal MC, Young AF, Perri MG, Patterson RE, Van Horn L, Assaf AR, Bowen DJ, Ockene J, Hays J. Wu L. predictors of dietary change and maintenance in the women's health initiative dietary modification trail. $J$ Am Diet Assoc. 2007;107:1155-65.

27. Hingle MD, Wertheim BC, Tindle HA, Tinker L, Seguin RA, Rosal MC, Thomson CA. Optimism and diet quality in the women's health initiative. Journal of academy of nutrition and dietetics. 2014;114:1036-45.

28. Gacek M. Individual differences as predictors of dietary patterns among menopausal women with arterial hypertension. Prz Menopauzalny. 2014; 13:101-8.

29. Giltay EJ, Geleijnse JM, Zitman FG, Buijsse B, Kromhout D. Lifestyle and dietary correlates of dispositional optimism in men: the Zutphen elderly study. J Psychosom Res. 2007;63:483-90.

30. Scheier MF, Carver CS. Optimism, coping and health: assessment and implications of generalized outcome expectancies. Health Psychol. 1985; 4:219-47.
31. Scheier MF, Carver CS, Bridges MW. Distinguishing optimism from neuroticism (and trait anxiety, self-mastery, and self-esteem): a re-evaluation of the life orientation test. J Pers Soc Psychol. 1994;6:1063-78.

32. Chang EC, Maydeu-Olivares A, D'Zurilla TJ. Optimism and pessimism as partially independent constructs: relationship to positive and negative affectivity and physiological well-being. Pers Indiv Differ. 1997;3:433-40.

33. Robinson-Whelen S, Kim C, MacCallum RC, Kiecolt-Glaser JK. Distinguishing optimism from pessimism in older adults: is it more important to be optimistic or not to be pessimistic? J Pers Soc Psychol. 1997;6:1345-53.

34. Kubzansky LD, Kubzansky PE, Maselko J. Optimism and pessimism in the context of health: bipolar opposites or separate constructs? Personal Soc Psychol Bull. 2004;30:943-56.

35. Herzberg PY, Glaesmer H, Hoyer J. Separating optimism and pessimism: a robust psychometric analysis of the revised life orientation test (LOT-R). Psychol Assessment. 2006:18:433-8.

36. Glaesmer H, Rief W, Martin A, Mewes R, Brahler E, Zenger M, Hinz A. Psychometric properties and population-based norms of the life orientation test revised (LOT-R). Br J Health Psychol. 2012;17:432-45.

37. Pänkäläinen $M$, Kerola $T$, Hintikka J. Pessimism and the risk for coronary heart disease among middle-aged and older Finnish men and women: a ten-year follow-up study. BMC Cardiovasc Disord. 2015;15:113.

38. Kubzansky LD, Sparrow D, Vokonas P. Kawachi I. is the glass half empty or half full? A prospective study of optimism and coronary heart disease in the normative aging study. Psychosom Med. 2001;63:910-6.

39. Tindle HA, Chang YF, Kuller LH, Manson JE, Robinson JG, Rosal MC, Siegle GJ, Matthews KA. Optimism, cynical hostility, and incident coronary heart disease and mortality in the Women's Health Initiative. Circulation. 2009;120:656-62.

40. Macdiarmid JI, Loe J, Kyle J, McNeill G. "It was an education in portion size". Experience of eating a healthy diet and barriers to long term dietary change. Appetite. 2013;71:411-9.

41. Bernera LA, Bocarslya ME, Hoebela BG, Avena NM. Baclofen suppresses binge eating of pure fat but not a sugar-rich or sweet-fat diet. Behav Pharmacol. 2009;20:631-4.

42. Lappalainen R, Kearneyc J, Gibneyc MA. Pan EU survey of consumer attitudes to food, nutrition and health: an overview. Food Qual Prefer. 1998; 9:467-78.

43. Paquette MC. Perceptions of healthy eating: state of knowledge and research gaps. Canadian Journal of Public Health. 2005:96:15-9.

44. Spronk I, Kullen C, Burdon C, O'Connor H. Relationship between nutrition knowledge and dietary intake. Br J Nutr. 2014;111:1713-26.

45. Bruzzese JM, Carcone Al, Lam P, Ellis DA, Naar-King S. Adherence to asthma medication regimens in urban African American adolescents: application of self-determination theory. Health Psychol. 2014;33:461-4.

46. Nabi H, Vahtera J, Singh-Manoux A, Pentti J, Oksanen T, Gimeno D, Elovainio M, Virtanen M, Klaukka T, Kivimäki M. Do psychological attributes matter for adherence to antihypertensive medication? The Finnish public sector cohort study. J Hypertens. 2008:26:2236-43.

47. Schroder KEE, Schwarzer R. Habitual self-control and management of health behavior among heart patients. Soc Sci Med. 2005:60:859-75.

48. Brewer BW, Cornelius AE, Van Raalte JL, Tennen H, Armeli S. Predictors of adherence to home rehabilitation exercises following anterior cruciate ligament reconstruction. Rehabilitation Psychology. 2013;58:64-72.

49. Shepperd JA, Maroto JJ, Pbert LA. Dispositional optimism as a predictor of health changes among cardiac patients. J Res Pers. 1996;30:517-34.

50. O'Brien LA, Thow MK, Rafferty D. Predicting adherence to phase III cardiac rehabilitation: should we be more optimistic? Br J Cardiol. 2009;16:250-3.

51. Ylöstalo PV, Ek E, Knuuttila MLE. Coping and optimism in relation to dental health behaviour - a study among Finnish young adults. Eur J Oral Sci. 2003;111:477-82.

52. Godin G, Côté J, Naccache H, Lambert LD, Trottier S. Prediction of adherence to antiretroviral therapy: a one-year longitudinal study. AIDS Care. 2005:17:493-504

53. Strack S, Carver CS, Blaney PH. Predicting successful completion of an aftercare program following treatment for alcoholism: the role of dispositional optimism. J Pers Soc Psychol. 1987;53:579-84.

54. Roy B, Diez-Roux AV, Seeman T, Ranjit N, Shea S, Cushman M. Association of Optimism and Pessimism with Inflammation and hemostasis in the multiethnic study of atherosclerosis (MESA). Psychosom Med. 2010;72:134-40.

55. Boehm JK, William DR, Rimm EB, Ryff C, Kubzansky LD. Association between optimism and serum antioxidants in the midlife in the United States study. Psychosom Med. 2013;75:2-10. 
56. Hankonen N, Vollmann M, Renner B, Absetz P. What is setting the stage for abdominal obesity reduction? A comparison between personality and health-related social cognitions. J Behav Med. 2010:415-22.

57. Nummela O, Sulander T, Helakorpi S, Haapola I, Uutela A, Heinonen H, Valve R, Fogelholm M. Register-based data indicated nonparticipation bias in a health study among aging people. J Clin Epidemiol. 2011;64:1418-25.

58. Schwab U, Uusitupa M. Diet heart controversies - quality of fat matters. Nutrition, Metabolism \& Cardiovascular Diseases. 2015;25:617-22.

Ready to submit your research? Choose BMC and benefit from:

- fast, convenient online submission

- thorough peer review by experienced researchers in your field

- rapid publication on acceptance

- support for research data, including large and complex data types

- gold Open Access which fosters wider collaboration and increased citations

- maximum visibility for your research: over $100 \mathrm{M}$ website views per year

At BMC, research is always in progress.

Learn more biomedcentral.com/submissions 